\title{
Rational Use of Medicine in Children- The Conflict of Interests Story. A Review
}

\author{
Klaus Rose, M.D., M.S. ${ }^{1, *}$, David Neubauer, M.D. ${ }^{2}$, and Jane M. Grant-Kels, \\ M.D. ${ }^{3}$ \\ ${ }^{1}$ klausrose Consulting, Pediatric Drug Development $\Xi^{2}$ More, Riehen, Switzerland; ${ }^{2}$ Department of Child, \\ Adolescent and Developmental Neurology, University Children's Hospital, Ljubljana, Slovenia; and \\ ${ }^{s}$ Department of Dermatology, UConn Health, Farmington, Connecticut, USA
}

\begin{abstract}
Background: United States (US) and European Union (EU) legislation attempts to counterbalance the presumed discrimination in pediatric drug treatment and development.
\end{abstract}

Methods: We analyzed the history of drug development, US/EU pediatric laws, and pediatric studies required by US/EU regulatory authorities and reviewed relevant literature.

\begin{abstract}
Abbreviations: AACAP, American Academy of Child and Adolescent Psychiatry; AAP, American Academy of Pediatrics; ALL, acute lymphoblastic leukemia; APA, American Psychiatric Association; CML, chronic myeloid leukemia; EMA, European Medicines Agency; EU, European Union; FDA, United States Food and Drug Administration; IFIs, invasive fungal infections; iPSP, initial pediatric study plan; ICMJE, International Committee of Medical Journal Editors; MDD, major depressive disorder; POS, partial onset seizures; PIP, pediatric investigation plan; PREA, Pediatric Research Equity Act; RACE, Research to Accelerate Cures and Equity (RACE) for Children Act; SSRIs, selective serotonin re-uptake inhibitors; T2DM, type 2 diabetes mellitus; US, United States of America; VLBW, very low birthweight.
\end{abstract}

Citation: Rose K, Neubauer D, Grant-Kels JM. Rational Use of Medicine in Children-The Conflict of Interests Story. A Review. Rambam Maimonides Med J 2019;10 (3):eoo18. Review. doi:10.5041/RMMJ.10371

Copyright: (C) 2019 Rose et al. This is an open-access article. All its content, except where otherwise noted, is distributed under the terms of the Creative Commons Attribution License (http://creativecommons.org/licenses/by/3.0), which permits unrestricted use, distribution, and reproduction in any medium, provided the original work is properly cited.

Author Contributions: Klaus Rose (KR), Jane Grant-Kels (JGK), and David Neubauer (DN) conceived the key thoughts of this manuscripts through common publications and discussions in 2018. KR wrote a first draft which was revised by JGK and DN. All authors have approved the final version of the manuscript.

Conflict of Interest: Klaus Rose has worked for 20 years in research and development/medical affairs in pharmaceutical industry and is now an independent consultant, advising pharmaceutical companies and academic institutions in all aspects of pediatric drug development, organizing scientific conferences, publishing, and more. He is also father of a severely handicapped daughter with a rare syndrome and is biased against empty governmental promises.

Jane Grant-Kels and David Neubauer declare no potential conflict of interest.

* To whom correspondence should be addressed. E-mail: klaus.rose@klausrose.net 
Results: The US and EU definitions of a child are defined administratively (rather than physiologically) as being aged $<17$ years and $<18$ years, respectively. However, children mature physiologically well before their seventeenth or eighteenth birthdays. The semantic blur for these differing definitions may indicate certain conflicts of interest.

Conclusions: Pediatric healthcare today is better than ever. Regulatory-related requirements for "pediatric" studies focus on labeling. Most of these studies lack medical usefulness and may even harm "pediatric" patients through administration of placebo and/or substandard treatment, despite the resultant publications, networking, patent extensions, and strengthened regulatory standing. Clinicians, parents, and ethics committees should be aware of these issues. New rules are needed to determine new pharmaceutical dose estimates in prepubescent patients, and when/how to clinically confirm them. Internet-based structures to divulge this information should be established between drug developers, clinicians, and regulatory authorities. A prerequisite for the rational use of pharmaceuticals in children would be to correct the flawed concept that children are discriminated against in drug treatment and development, and to abandon separate "pediatric" drug approval processes.

KEY WORDS: Developmental pharmacology, juvenile idiopathic arthritis, pediatric drug development, pediatric investigation plan (PIP), pediatric oncology

\section{INTRODUCTION}

Preconceptions and long-standing traditional treatments can be tenacious and difficult to change. There have been many incorrect opinions related to a number of pediatric conditions, including the idea that depression, ${ }^{1,2}$ schizophrenia, ${ }^{3}$ adult-type cancers, 4,5 and more are not found in children. Today, these are recognized pediatric conditions. Prescription medications that have been United States (US) Food and Drug Administration (FDA)-approved in adults, but not in children, represent another area fraught with misconceptions.

Legislation in the USA and the European Union (EU) has sought to counterbalance the presumed discrimination in pediatric drug development and treatment. ${ }^{6,7}$ The need for such development has been stressed and endorsed by academia, ${ }^{8}$ regulatory authorities, ${ }^{9-12}$ and the pharmaceutical industry. ${ }^{13-15}$ The FDA and the European Medicines Agency (EMA) require pediatric studies, many of which have worldwide recruitment, ${ }^{16-19}$ paid for by pharmaceutical companies.

In 1900, few efficient systemic drugs existed, and industrial production of antibiotics only began during the Second World War. Today, drug efficacy and benefit-risk ratios are not only well documented but also undergo an extensive approval process. Pharmaceuticals have a huge impact on society, ranging from intended medical use to their societal and economic impact: prescribed by physicians, pharmacy sales, public debates, insured versus uninsured costs and reimbursement, healthcare jobs, therapeutic expectations by the public, and more. In addition, the role of regulatory authorities has transitioned from administrative organizations to powerful institutions, and clinical studies now have a major role in the drug approval process. Drugs both make lethal diseases treatable, ${ }^{20,21}$ and create great wealth for the pharmaceutical industry.

Originally "drug labels" (labeling) simply described the packaged medication. Since 1906, drug labeling has evolved to include therapeutic characteristics. ${ }^{22}$ Responding to the 1962 thalidomide disaster, FDA approval became based upon preapproval clinical studies, a principle now accepted worldwide. ${ }^{23}$ The term "off-label" emerged in $1988,{ }^{24}$ reflecting the FDA's growing administrative influence. Although US legislation does not prohibit off-label use or off-label prescriptions, it does forbid interstate commerce of misbranded food and drugs. ${ }^{22}$ The FDA dislikes off-label use and promotion of such, and has collected billions of dollars in fines for it. ${ }^{22}$ However, this conflicts with the physician's right of discretion and is hotly debated in the courts. ${ }^{22,25}$

Central regulatory authority involvement has changed and shaped society's relationship with medications. Clinical studies are regarded as the gold standard for drug treatment decisions. Participation in clinical studies and publications have become key factors in a clinicians' career. Many studies are sponsored by companies that anticipate retrieval of invested money via post-approval sales. 
Conflicts of interest exist when professional judgment concerning a primary interest, including patient welfare or the validity of research, may be influenced by another interest. Healthcare, approval of effective drugs, and the pharmaceutical industry itself are entangled in a world where conflicts of interest abound. Beyond financial compensation, clinicians profit from participation in international studies by related international meetings, networking, conference presentations, and publications. "Evidence-based medicine" suggests that medical decisions are based on evidence. ${ }^{26,27}$ However, most studies are co-designed by clinicians and industry representatives with naturally different goals. Evidence-based medicine is lauded, ${ }^{27}$ relativized/ ridiculed, ${ }^{28}$ or openly criticized. ${ }^{29}$ To prevent fraud, only studies listed in a publicly available registry before study initiation are considered for publication in better peer-reviewed journals. ${ }^{27}$

This review discusses-and thereby opens a Pandora's box for-these issues.

\section{MATERIALS AND METHODS}

We reviewed literature related to the history of drug development, the FDA approval process, and how children entered into this equation. We examined the ramifications of international recruitment, EU pediatric legislation, exemplary clinical areas for pediatric studies triggered by regulatory decisions, and how academia reacted and behaved. Regulatory documents were internet-retrieved.

\section{RESULTS}

\section{Children as "Therapeutic Orphans"}

The concept of children as "therapeutic orphans" began in 1962, when the FDA started to control prescription medicine advertising and corporate lawyers started inserting specific pediatric warnings into drug labeling..$^{30-32}$ These warnings were based on reported toxicities in preterm newborns treated with antibiotics in the 1950s, and intended to mitigate lawsuits in the litigious USA. ${ }^{11,32}$ However, Shirkey, the first chairman of the American Academy of Pediatrics (AAP) committee on drugs, claimed that these warnings deprived children of modern drugs. ${ }^{6}$ Soon after, the AAP and FDA began to closely collaborate. ${ }^{8}$ In 1979, the FDA defined children as being 16 years or under $(<17) .7$ Since 1997, US law rewards pediatric studies with 6-month patent extensions, for which companies must accept and execute FDA “written requests.” Furthermore, since
2003, the FDA has been authorized to mandate pediatric studies also without reward. 7 This concept pretends that administratively defined "children" remain as immature and vulnerable as preterm newborns until they are adults. ${ }^{31-34}$

\section{Publications Supporting the FDA Stance}

The FDA's concept is discussed and justified in several papers, claiming that: (1) drugs prescribed for children were not sufficiently studied in children; (2) pharmaceutical companies have limited interests to study drugs in "children;" and (3) lack of pediatric studies and pediatric labeling leads to additional risks. ${ }^{4,5,35-38}$ Most publications do not discuss treatment in preterm newborns but in the "pediatric population" (<17 years). However, 15-year-old adolescents are legally underage, administratively FDAdefined as "children," but, with regard to metabolism, are no longer children. Snyder and colleagues believed that dosing in "neonates, infants, toddlers, children, and adolescents" requires understanding of pharmacokinetics and pharmacodynamics in each age group, ${ }^{4}$ although the reference cited states the opposite about adolescents, who need adult dosages. 39

The focus of pediatric FDA-requested studies has been regulatory, not clinical. A connection between pediatric labeling, improved clinical use, and avoidance of adverse events is claimed;4,5,35-38 FDA authors also claim that physicians must decide between withholding treatment proven effective in older patients, or prescribing off-label, with doses based on untested hypotheses, placing children at increased risk of adverse events. ${ }^{38}$ A 1977 AAP guideline states it is "unethical to adhere to a system which forces physicians to use therapeutic agents in an uncontrolled experimental situation virtually every time they prescribe for children." ${ }^{40(p p 91-92)}$ These positions would be true if children remained as vulnerable as premature newborns until their seventeenth birthday.

Clearly, the needs of very young children versus older children have been confused. The limited awareness of infant vulnerability to drugs in the 1950 /1960s has been translated into a generalized warning of alleged treatment dangers in "children," ignoring physical maturation. The literature maintains this semantic blur for different meanings of "children," i.e. the very young versus the FDAdefined child $<17.4,5,35,38$ This confusion led to FDA requests for separate pediatric efficacy and safety studies, ${ }^{41}$ although most are clinically and medically unjustified. 


\section{The EU Steps In}

In 2006, the EU defined "children" as being under 18 years of age $(<18) .4^{2}$ Pediatric investigation plans (PIPs) were required for every new drug, unless the targeted disease was on the list of "class waivers," i.e. conditions not found in children. The EMA has been continuously revising this list since 2008 and removed, for example, adolescent melanoma.

The EMA PIP scheme is mechanistic, often requiring placebo-controlled efficacy studies for multiple sclerosis, 43 allergic rhinoconjunctivitis, 44 and leukemia45 drugs in the "pediatric" population. Open-label studies are required on pharmacokinetics, safety, and activity for acute myelogenous leukemia (AML) and/or chronic myeloid leukemia (CML) pharmaceuticals, 45 as well as many compounds treating acute lymphoblastic leukemia (ALL). International "pediatric" studies with centers in Switzerland, ${ }^{16}$ the USA and Russia, ${ }^{17}$ China, ${ }^{18}$ Germany, ${ }^{46}$ and Slovenia ${ }^{19}$ include PIP-required "pediatric" studies for drugs treating several conditions, including juvenile idiopathic arthritis and diabetes. While the FDA has relented in areas such as atopic dermatitis 47 and epilepsy,48,49 the EMA continues to demand separate "pediatric" studies.

\section{Examples from Specific Clinical Areas}

The confusion engendered by the administrative definitions of "child" and the bureaucracy involved for pharmaceutical approvals is evident in a number of clinical areas.

\section{Depression}

Use of antidepressants in pediatrics has a confusing history that leaves physicians in a quandary. Contributing to this is the administrative definition of "children," which prevents young patients from receiving effective depression treatment. Suicide in young persons is a higher-ranked cause of death than malignomas. $5^{\circ}$ Suicide is often caused by depression, hence antidepressive treatment is of high clinical importance. As shown in Table 1, childhood depression was not considered a reality, although today its existence is undisputed. ${ }^{51-53}$ The FDA became involved in an attempt to reduce suicidality in children, to no avail.

Today, pediatricians and psychiatrists treating depression in minors must either follow regulatory recommendations or administer off-label prescriptions for potentially life-saving medications. The American Psychiatric Association (APA) stated that

Table 1. Changes in View and Management of Depression in Young Persons.

\begin{tabular}{|c|c|}
\hline Date/Time Period & Stance and Management \\
\hline 1970s & Childhood depression considered non-existent ${ }^{1}$ \\
\hline 1990s & Childhood depression undisputed ${ }^{1,51-53}$ \\
\hline Since 1997 & $\begin{array}{l}\text { - FDA rewards } 23 \text { placebo-controlled pediatric studies to test efficacy of } \\
\text { antidepressants in "children" } \\
\text { - The United States Treatment of Adolescents with Depression Study (TADS) } \\
\text { is nationally funded } \\
\text { - Pediatric antidepressant efficacy studies with mixed results }{ }^{1,54-59}\end{array}$ \\
\hline 2004 & $\begin{array}{l}\text { - FDA issues black-box warning for antidepressants in children, adolescents, } \\
\text { and young adults because of their association with suicidality } \\
\text { - Studies referenced by FDA not designed to assess suicidality }{ }^{58,59} \\
\text { - Decrease in prescriptions for SSRIs and antidepressants in young patients, } \\
\text { and increased incidence of suicide }{ }^{58,59} \\
\text { - Fluoxetine the only antidepressant FDA-approved in "children" } 60,61\end{array}$ \\
\hline 2009 & $\begin{array}{l}\text { FDA approves escitalopram for major depressive disorder (MDD) in } \\
\text { "children" } 62\end{array}$ \\
\hline To date & $\begin{array}{l}\text { Academic researchers continue to accept the division into adult versus } \\
\text { "pediatric" populations; they perform studies, analyses, meta-analyses, and } \\
\text { demand more research }{ }^{63-67}\end{array}$ \\
\hline
\end{tabular}


antidepressants save lives, with "no care at all" being the greatest threat to a depressed child. It expressed concerns that the black-box warning could reduce appropriate prescribing. The American Academy of Child and Adolescent Psychiatry (AACAP) has stated that the black-box warning was inconsistent with research and clinical experience. 54 However, representative pediatric and psychiatric bodies have not acknowledged the suicidal consequences of the blackbox warning, nor have they challenged the definition of "children." 32 Furthermore, the committee decision leading to the FDA's black-box warning was not unanimous, ${ }^{1}$ and there was disagreement between clinicians and the FDA's interpretation of the related studies.

\section{Oncology}

Pediatric oncology studies triggered by the FDA endorse the semantic blur of bureaucratically defined "children." These studies assumed that, except for CML, the biology of malignancies differs in adults versus children.4,5 The exception for imatinib was made because it was the first personalized anticancer drug for CML and was from early on known to work in both adults and children. ${ }^{68}$

The FDA issued 25 written requests for carcinoma drugs; only clofarabine, everolimus, and imatinib received pediatric labels. 4 These study requests were made despite the prior extensive (and successful) use of the investigated pharmaceuticals in different combinations of up to 13 anticancer drugs in pediatric oncology. ${ }^{69}$

The pemetrexed written request asked to investigate "refractory or relapsed pediatric malignancies" in infants $>1$ month to adolescents. $7^{\circ} \mathrm{A}$ subsequent pemetrexed publication reported its tolerance in "children and adolescents with refractory solid tumors, including CNS tumors," with no evidence of objective anti-tumor activity found in the studied childhood tumors; however, the publication failed to mention the study's regulatory background. ${ }^{71}$

All but one of the FDA-triggered oncology studies were open-label with one chemotherapeutic agent. 5 The only FDA-triggered randomized pediatric oncology study was on the addition of docetaxel to the combination of cisplatin and 5 -fluorouracil for nasopharyngeal carcinoma (NPC). 4 The academic publication described NPC as a malignancy in children and adolescents and did not reveal the study's regulatory background. ${ }^{72}$ However, NPC affects children, adolescents, and adults. 73,74 The study showed no difference in the treatments ${ }^{72}$ but led to a patent extension for the sponsor. 75

One FDA-program rewarded pediatric melanoma studies with ipilimumab, but 13 PIPs demanded "pediatric" studies in solid tumors, including melanoma. Two PIP-demanded "pediatric" melanoma studies had to be terminated because monotherapy with ipilimumab and vemurafenib, respectively, became sub-standard and recruitment waned. ${ }^{11,32,34}$ Five studies are still recruiting worldwide. ${ }^{31,32}$

Fludarabine studies revealed relatively low efficacy. ${ }^{7-79}$ Labeling was not changed, but the company received a patent extension, as did the others that fulfilled FDA written requests.75,80

The FDA-required pediatric oncology studies were not designed to promote survival and quality of life, as did the earlier studies performed by the pediatric oncology researchers, ${ }^{69,81}$ but to provide regulatory coverage for compounds already used successfully by clinicians. Many academic publications describe their respective study rationale as a scientific challenge. $77,82-85$ The need for separate "pediatric" studies is taken for granted and not critically discussed. The reason why companies sponsor(ed) such studies was/is omitted.

The FDA-requested pediatric oncology studies were mostly performed in heavily pretreated, relapsed or refractory patients, 5 raising inappropriate hopes for families and patients. ${ }^{78}$ Some studies resulted in labeling changes, others not. Clofarabine studies did not improve life expectancy or symptoms,79 but the manufacturer received a patent extension. 75

The FDA-requested pediatric oncology studies were not scientifically motivated, in contradistinction to the pediatric oncology networks studies. ${ }^{69,81}$ Instead, they provided patent extensions for the sponsoring companies. ${ }^{75,80}$ In written requests, the FDA misleadingly stated that study participation was standard-of-care in pediatric oncology. ${ }^{70}$ While this was/is true for therapeutically focused studies, ${ }^{69,81}$ this is not true for regulatory FDA-triggered studies.

Finally, not all malignancies in underage patients are "pediatric" cancers-for example, conventional melanoma, ${ }^{86}$ or ALL, where re-programmed leukocytes destroy ALL cells. ${ }^{20}$ Tisagenlecleucel is FDA/ EMA-approved in recurrent or refractory B-cell precursor ALL in $\leq 25$-year-olds; ${ }^{21}$ this age limit reflects that young patients' leukocytes are easier to 
re-program than those of older patients. Also this age limit has a certain degree of arbitrarity, but it is not justified by blurring legal and physiological terms. Furthermore, tisagenlecleucel is not a "pediatric" drug for a "pediatric" disease; it is a drug that works in relatively young patients.

\section{Hypertension}

Hypertension, frequent in adults, is rare in younger patients. The FDA rewarded "pediatric" antihypertensive studies, ${ }^{87}$ although hypertension did not reflect a serious gap in pediatric healthcare. ${ }^{88}$ The patients ranged from 6 to 16 years ${ }^{87}$ and were recruited by administrative age limits. However, beta-blockers work equally in 18- or 15-year-olds; hence, effective treatment was and is denied to adolescents who could profit from them.

\section{Diabetes}

Four oral drugs for type 2 diabetes mellitus (T2DM) have been FDA-evaluated for "pediatric" use: metformin, glimepiride, rosiglitazone, and metformin+ glyburide. Each drug reduced glycemic parameters; three failed to reach the FDA-demanded efficacy threshold, and only metformin was FDA-approved in "children." These studies did not contribute to better diabetes treatment in children. The academic publication described "pediatric drug development" as what it is: regulatory approval/non-approval of drugs whose efficacy in humans is already well proven. ${ }^{89}$

\section{Neonatology and Infectious Diseases}

Neonatology has continuously advanced..$^{\circ}$ Neonatal studies are demanded by representatives of "pediatric drug development." 8,36 In very-low-birthweight (VLBW) neonates, antifungals are already used clinically, not with a regulatory focus, but with a focus on patients' wellbeing. ${ }^{11}$

Chloramphenicole toxicity in neonates is well known. The toxicities in preterm newborns that triggered industry's pediatric warnings occurred with antibiotics. 33 Among the current pediatric clinical challenges in antifungal treatment are prophylaxis and treatment of invasive fungal infections (IFIs) in premature and VLBW neonates, candidemia, and meningoencephalitis in neonates, and prophylaxis, empiric therapy, and targeted antifungal therapy in children with immunodeficiencies. ${ }^{91}$ The PIPs for the antifungals posaconazole, voriconazole, and isavuconazonium demand regulatory efficacy confirmation of these compounds in underage patients. Antifungal prevention and treatment is done today, without separate approval in VLBW neonates. Hence, there is no medical sense in demanding separate proof of efficacy of antifungals for young patients.

\section{Multiple Sclerosis}

Lacking scientific rationale are the FDA and EMA requirements for active-controlled or even placebocontrolled comparisons of anti-inflammatory compounds in multiple sclerosis (MS). 43 While the clinical course of pediatric versus adult MS is different, the disease itself is inflammatory. ${ }^{2}$ The FDA/EMA assume that drugs not separately approved might not work before a minor turns 17 or 18 .

\section{Pediatric Clinical Pharmacology}

Pediatric clinical pharmacology had and has a key role in promoting separate "pediatric" studies. ${ }^{8}$ In Europe, many publications claimed that off-label drug use resulted in higher rates of adverse events. ${ }^{93}-95$ However, the major statistically significant finding of Turner et al. was the number of medications administered to patients, not their unlicensed or off-label status. 94 In another study, the data "suggest an increasing risk of adverse drug reactions related to off-label drug use," but the authors emphasize that this risk would be acceptable should further studies confirm the potential benefit of such drug use.95 The claim that off-label use "doubles the frequency of adverse drug reactions" 93 was not and is not based on data.

\section{Demands to Expand Current Pediatric Legislation}

The multi-stakeholder group "ACCELERATE" (www.accelerate-platform.eu/) discusses pediatric oncology studies. Without acknowledging the flaws of US/EU pediatric legislation, it recommends inclusion of adolescents in promising adult cancer studies, ${ }^{96}$ a suggestion also recommended by Geoerger et al. following the terminated "pediatric" ipilimumab study. 97

Pediatric researchers and regulatory/industry representatives propose switching from organspecific PIPs to a "mode of action" approach, ${ }^{98-100}$ without acknowledging the flaws of US/EU pediatric laws. The "mode of action" approach would lead to more "pediatric" studies with modern anti-cancer compounds. The tisagenlecleucel PIP EMEA001654-PIPo1-14-Mo2 demands separate "pediatric" studies despite its approval in young patients. 
The newest EMA class waiver changes ${ }^{101}$ will lead to "pediatric" hepatic carcinoma studies. Comparable to conventional melanoma, hepatic carcinoma rarely occurs in patients under 18 years of age. Separate "pediatric" studies based on artificial age limits are questionable.

\section{Political Stage and Further Plans}

The 2016 FDA report ${ }^{102}$ and a resolution of the European Parliament ${ }^{103}$ ask for an expansion of pediatric legislation. The US "Research to Accelerate Cures and Equity" (RACE) for Children Act will come into force in 2020. ${ }^{104-106}$. It will remove current restrictions that exclude orphan drugs from FDA-mandated pediatric trials, expanding the FDA's authority to demand "pediatric" cancer studies. It is endorsed by Nature journal and more than 100 advocacy organizations. ${ }^{107}$ It will strengthen the FDA's administrative power and trigger more "pediatric" studies, but will not advance pediatric cancer treatment.

\section{DISCUSSION}

In those rare diseases for which pediatric therapy is different than in adults, e.g. bisphosphonates for osteogenesis imperfecta, 48,49 or anastrozole for McCune-Albright syndrome, ${ }^{108}$ separate pediatric efficacy studies make sense. However, for most diseases occurring in adults and children, once medication efficacy is established, adolescents can usually be treated with adult doses. Dose-finding is necessary only for prepubescent children, and, clearly, neonates need specific attention. Hence, pharmaceutical companies should include adolescents in pivotal studies.

In some areas, the FDA has become less dogmatic: for partial onset seizures (POS) epilepsy, efficacy extrapolation is accepted from adults down to 4year-olds; 48 for topical treatment of atopic dermatitis pivotal studies have been accepted with patients aged 2-79 years. ${ }^{47}$

As stated above, "pediatric drug development" originated as a response to the US thalidomide catastrophe. New procedures were imposed on the administratively defined pediatric population in an attempt to keep dangerous substances from the market and improve pediatric healthcare; the main proponent were the AAP and the FDA, endorsed by the clinical community. For many practitioners common sense prevailed, as noted already by Shirkey in 1968: most clinicians ignored the pediatric warnings. ${ }^{6}$ The flawed US approach was further augmented by the EU. With development of more efficacious treatments, subjecting young patients to traditional "standard of care" or placebo is more likely to result in substandard treatment. Young patients suffering from lethal conditions can actually be directly harmed by being placed in comparator or placebo groups.

The key issue is the administrative definition of the "pediatric" population: $<17 /<18.7,31,32$ "Pediatric drug development" requirements are based on a semantic blur of different physiological, administrative, and legal meanings of the word "child." The "moral imperative" 33 for "pediatric" studies appeals to protective instincts toward young children. Endorsed by the clinical community, the translation of this concept into law and the bestowal of executive power to the FDA created incentives for questionable, expensive, and harmful "pediatric" studies. The EU followed, augmented, and expanded on the US precedent. The mandatory US law "Pediatric Research Equity Act" (PREA)7 does not apply to orphan designations; EU PIPs are also required for rare diseases, vaccines, and biologics. The stronger mandate for the EMA reflected back on the FDA which now asks for "initial Pediatric Study Plans" (iPSPs); at least the iPSP template ${ }^{109}$ is less demanding than its PIP counterpart. ${ }^{110}$

The flawed definition of "children"-supplemented by FDA assumptions about pediatric cancer ${ }^{4}$ and juvenile "suicidality" 58,59 -has confused the clinical world. Procedurally, "pediatric" studies are well documented, but they are based on a flawed concept. There were and are pockets of resistance, ${ }^{28,88,111,112}$ but open intellectual challenges of FDA/EMA pediatric activism are still rare. ${ }^{16-19,31,32,43-46}$ The EMA's claim that it made more medicines "available" for children ${ }^{10}$ is misleading. "Available" means EMAissued pediatric labels: a regulatory, not a clinical achievement.

\section{CONCLUSIONS}

Many publications on "pediatric" studies pretend to investigate a scientific question and omit mentioning that the studies were FDA/EMA-required.77,82-85,89 Others discuss "pediatric drug development," but the discussed studies are only regulatory in nature. ${ }^{8}$

Ongoing research is required in neonates. Institutional review boards/ethics committees should re-assess all ongoing pediatric studies. Those 
found to be questionable should be suspended and newly submitted questionable ones rejected.

Based on this review, we believe that (1) treatment of neonates, infants, children, adolescents, and adults is today better than ever in history; (2) the justifications for separate "pediatric drug development" are flawed; (3) these flaws are not a conspiracy, but reflect the complex path toward rational use of drugs, biologics, devices, and technology; (4) the flawed concept of "pediatric drug development" has created many conflicts of interest since becoming US law; (5) this flawed US-born concept was adopted and augmented by the EU; (6) the EU further potentiated conflicts of interest of many parties and institutions that profit from separate "pediatric" studies; (7) the EU exaggerations finally facilitated detection of the fundamental flaws; and (8) academic critical reflections have not pinpointed the flaws of "pediatric drug development." 88,112

It is possible that underlying conflicts of interest will trigger angry responses from individuals, parties, and institutions; the ensuing public debate could rock public trust in science and institutions. Nevertheless, conflicts of interest are not only financial and do not follow traditional boundaries of institutions; hence, protective mechanisms against fraud and professional misconduct are needed and should be reflected in required revisions to US/EU pediatric legislation. Also, the International Committee of Medical Journals Editors (ICMJE) guidelines should be accordingly revised. ${ }^{27}$ These steps will eventually facilitate better access to efficient drugs, biologics, devices, diagnostics, and breakthroughs in young patients.

The current framework allowed and allows pediatric researchers on the one hand to support pediatric legislation and demand more pediatric studies, but on the other hand to omit, in the resulting study publications, the regulatory background and the reason companies had to sponsor the studies. ${ }^{87} \mathrm{In}$ the future, regulatory demands that trigger "pediatric" studies should be clearly mentioned in academic publications. The ICMJE guidelines should be accordingly revised. ${ }^{27}$ Today, clinicians have to choose between prescribing effective treatment off-label, or prescribing substandard treatment on-label. Dosefinding in prepubescent children is necessary, but not separate drug approval.

The FDA- and EMA-triggered "pediatric" studies might represent the largest abuse of patients in medical research, dwarfing even the atrocities unveiled by Beecher in 1966 and other projects that led to the Belmont Report. ${ }^{113-115}$

New guidelines are needed, including when and how drug developers should estimate doses in prepubescent patients and when and how to confirm them in "opportunistic" settings. ${ }^{116,117}$ Internet-based information structures for dose recommendations of new drugs in prepubescent patients will technically be rather easy to establish in collaboration with drug developers, clinicians, and regulatory authorities.

Finally, a prerequisite to moving ahead is requiring the FDA, EMA, AAP and its European counterparts to reject the flawed concept of children as "therapeutic orphans" and the need for separate drug approval in "children." This flawed concept is now outdated and should be discarded.

\section{REFERENCES}

1. Varley CK. Treating depression in children and adolescents: what options now? CNS Drugs 2006;20:113. Crossref

2. Healy D, Le Noury J, Jureidini J. Paediatric antidepressants: benefits and risks. Int J Risk Saf Med 2019;30:1-7. $\underline{\text { Crossref }}$

3. Driver DI, Gogtay N, Rapoport JL. Childhood onset schizophrenia and early onset schizophrenia spectrum disorders. Child Adolesc Psychiatr Clin N Am 2013;22:539-55. Crossref

4. Snyder KM, Reaman G, Avant D, Pazdur R. The impact of the written request process on drug development in childhood cancer. Pediatr Blood Cancer 2013;60:531-7. Crossref

5. Wharton GT, Murphy MD, Avant D, et al. Impact of pediatric exclusivity on drug labeling and demonstrations of efficacy. Pediatrics 2014;134:e512-18. Crossref

6. Shirkey H. Therapeutic orphans. J Pediatr 1968;72: 119-20.

7. Hirschfeld S, Saint-Raymond A. Pediatric regulatory initiatives. Handb Exp Pharmacol 2011;205:245-68. Crossref

8. Ward RM, Benjamin DK, Davis JM, et al. The need for pediatric drug development. J Pediatr 2018;192: 13-21. Crossref

9. Mulberg AE, Murphy MD, Dunne J, Mathis LL, eds. Pediatric Drug Development: Concepts and Applications. 2nd ed. Chichester, UK: John Wiley \& Sons, Ltd; 2013.

10. Tomasi PA, Egger GF, Pallidis C, Saint-Raymond A. Enabling development of paediatric medicines in 
Europe: 10 years of the EU paediatric regulation. Pediatr Drugs 2017;19:505-13. Crossref

11. Mentzer D. Progress review of the European paediatric regulatory framework after six years of implementation. Int J Pharm 2014;469:240-3. Crossref

12. Rocchi F, Tomasi P. The development of medicines for children: part of a series on pediatric pharmacology, guest edited by Gianvincenzo Zuccotti, Emilio Clementi, and Massimo Molteni. Pharmacol Res 2011;64:169-75. $\underline{\text { Crossref }}$

13. Bucci-Rechtweg C. Enhancing the pediatric drug development framework to deliver better pediatric therapies tomorrow. Clin Ther 2017;39:1920-32. Crossref

14. Pharmaceutical Research and Manufacturers of America. Research \& Development Pediatrics. Available at: https://onphr.ma/2IcSv4U (accessed February 26, 2019).

15. European Federation of Pharmaceutical Industries and Associations (EFPIA). EFPIA welcomes paediatric medicines regulation report and reiterates its commitment to progress in this area. October 27, 2017. Available at: http://bit.ly/2JUDRTo (accessed February 26, 2019).

16. Rose K, Grant-Kels JM. Questionable international pediatric studies with Swiss participation. Swiss Med Wkly 2018 March 19. Available at: http://bit.ly/ 2IceGbs (accessed February 26, 2019).

17. Rose K, Grant-Kels JM. Questionable international pediatric studies in the United States and Russia triggered by regulatory authorities. Asian Journal of Research in Medical and Pharmaceutical Sciences 2018;3:1-10. Available at: http://bit.ly/2HRJv6s (accessed February 26, 2019).

18. Rose K, Grant-Kels JM. Questionable industrysponsored pediatric studies in China triggered by United States of America (US) and European Union (EU) regulatory authorities. SciFed Pharmaceutics Journal 2018,1:2. Available at: http://bit.ly/317BySi (accessed February 26, 2019).

19. Rose K, Neubauer D, Grant-Kels JM. Questionable industry-sponsored postneonatal pediatric studies in Slovenia. Current Ther Res 2019; in press. Available at: Crossref (accessed February 26, 2019).

20. Maude SL, Laetsch TW, Buechner J, et al. Tisagenlecleucel in children and young adults with B-cell lymphoblastic leukemia. N Engl J Med 2018;378: 439-48. Crossref

21. US Food and Drug Administration. Highlights of prescribing information for KYMRIAH (tisagenlecleucel). Available at: http://bit.ly/2JT6L66 (accessed May 21, 2019).
22. Janssen W. A historical perspective on off-label medicine: from regulation, promotion, and the first amendment to the next frontiers. SSRN Electronic Journal 2014, June 16. $\underline{\text { Crossref }}$

23. Rägo L, Santoso B. Drug Regulation: History, Present and Future. In: van Boxtel CJ, Santoso B, Edwards IR, eds. Drug Benefits and Risks: International Textbook of Clinical Pharmacology, revised 2nd ed. Uppsala, Sweden: IOS Press and Uppsala Monitoring Centre; 2008:65-77. Available at: http://bit.ly/ 2Z8kcCX (accessed February 26, 2019).

24. Plate V. The impact of off-label, compassionate and unlicensed use on health care laws in preselected countries. Dissertation for doctoral degree, Bonn University, 2009. Available at: http://bit.ly/2MrZSL9 (accessed February 26, 2019).

25. Mazina N. Recent developments in off-label use and legal implications to physicians. American Bar Association, Health Law Section 2017;14(3). Available at: http://bit.ly/2Kp73kv (accessed February 26, 2019).

26. Sackett DL, Rosenberg WM, Gray JA, Haynes RB, Richardson WS. Evidence based medicine: what it is and what it isn't. BMJ 1996;312:71-2. Crossref

27. International Committee of Medical Journal Editors. Recommendations for the conduct, reporting, editing, and publication of scholarly work in medical journals. 2018. Available at: http://bit.ly/2WKCPiu (accessed February 26, 2019).

28. Smith GC, Pell JP. Parachute use to prevent death and major trauma related to gravitational challenge: systematic review of randomized controlled trials. BMJ 2003;237:1459-61. $\underline{\text { Crossref }}$

29. Stalder H. Evidence-based medicine: nicht immer so evident! [Evidence-based medicine: not always so evident!] Schweizerische Ärztezeitung 2017;98:1316 [German]. Crossref

30. Donohue J. A history of drug advertising: the evolving roles of consumers and consumer protection. Milbank Q 2006;84:659-99. $\underline{\text { Crossref }}$

31. Rose K, Grant-Kels JM. Pediatric melanoma - the whole (conflicts of interest) story. Int $\mathrm{J}$ Womens Dermatol 2018;5:110-15. Available at: Crossref (accessed February 26, 2019).

32. Rose K, Grant-Kels JM. The meanings of "pediatric drug development.” Ther Innov Regul Sci 2018; Dec 9 [Epub ahead of print]. $\underline{\text { Crossref }}$

33. Committee on Drugs. Guidelines for the ethical conduct of studies to evaluate drugs in pediatric populations. Pediatrics 1995;95:286-94. Available at: http://bit.ly/2ZoCZjm (accessed February 26, 2019). 
34. Rose K, Walson PD. Do pediatric investigation plans (PIPs) advance pediatric healthcare? Paediatr Drugs 2017;19:515-22. Crossref

35. Roberts R, Rodriguez W, Murphy D, Crescenzi T. Pediatric drug labelling: improving the safety and efficacy of pediatric therapies. JAMA 2003;290: 905-11. Crossref

36. Ward RM, Kern SE. Clinical trials in neonates: a therapeutic imperative. Clin Pharmacol Ther 2009; 86:585-7. $\underline{\text { Crossref }}$

37. Benjamin DK Jr, Smith PB, Murphy MD, et al. Peerreviewed publication of clinical trials completed for pediatric exclusivity. JAMA 2006;296:1266-73. Crossref

38. Benjamin DK. Safety and transparency of pediatric clinical trials. Arch Pediatr Adolesc Med 2009; 163:1080-6. $\underline{\text { Crossref }}$

39. Kearns GL, Abdel-Rahman SM, Alander SW, Blowey DL, Leeder JS, Kauffman RE. Developmental pharmacology--drug disposition, action, and therapy in infants and children. N Engl J Med 2003;349:115767. $\underline{\text { Crossref }}$

40. American Academy of Pediatrics Committee on Drugs. Guidelines for the ethical conduct of studies to evaluate drugs in pediatric populations. Pediatrics 1977;60:91-101. Available at: http://bit.ly/2If3HOB (accessed February 26, 2019).

41. Food and Drug Administration [website]. Written Requests Issued. (Content current as of: 06/15/2018) Available at: http://bit.ly/2JZkBnN (accessed February 26, 2019).

42. European Union. Regulation (EC) No 1901/2006 of the European Parliament and of the Council of 12 December 2006 on Medicinal Products for Paediatric Use and amending Regulation (EEC) No 1768/92, Directive 2001/20/EC, Directive 2001/83/EC and Regulation (EC) No 726/2004. Official Journal of the European Union 2006;Dec. 27: L378/1-19. Available at: http://bit.ly/2YZnuYQ (accessed February 26, 2019).

43. Rose K, Müeller T. Children with multiple sclerosis should not become therapeutic hostages. Ther Adv Neurol Disord 2016;9:389-95. $\underline{\text { Crossref }}$

44. Rose K, Kopp MV. Pediatric investigation plans for specific immunotherapy: questionable contributions to childhood health. Pediatr Allergy Immunol 2015; 26:695-701. Crossref

45. Rose K, Walson PD. The contributions of the European Medicines Agency and its pediatric committee to the fight against childhood leukemia. Risk Manag Health Policy 2015;8:185-205. $\underline{\text { Crossref }}$
46. Rose K. Kinder brauchen nur sinnvolle Studien [Children need only reasonable clinical studies]. Pädiatrische Praxis 2018;90:705-16 [German].

47. US Food and Drug Administration. FDA approves Eucrisa for eczema. 2016;December 14. Available at: http://bit.ly/2Z2WVlK (accessed February 26, 2019).

48. Sun H, Temeck JW, Chambers W, Perkins G, Bonnel R, Murphy D. Extrapolation of efficacy in pediatric drug development and evidence-based medicine: progress and lessons learned. Ther Innov Regul Sci 2017;2017:1-7. Crossref

49. Dunne J, Rodriguez WJ, Murphy MD, et al. Extrapolation of adult data and other data in pediatric drugdevelopment programs. Pediatrics 2011;128:e1242-9. Crossref

50. National Center for Injury Prevention and Control. 10 Leading Causes of Death by Age Group, United States - 2016. Available at: http://bit.ly/2KtvfCi (accessed February 26, 2019).

51. Jensen PS, Ryan ND, Prien R. Psychopharmacology of child and adolescent major depression: present status and future directions. J Child Adolesc Psychopharmacol 1992;2:31-45. Crossref

52. Birmaher B, Ryan ND, Williamson DE, et al. Childhood and adolescent depression: a review of the past 10 years. Part I. J Am Acad Child Adolesc Psychiatry 1996;35:1427-39. Crossref

53. Henry A, Kisicki MD, Varley C. Efficacy and safety of antidepressant drug treatment in children and adolescents. Mol Psychiatry 2012;17:1186-93. $\underline{\text { Crossref }}$

54. Dawson RS. Depression in children and adolescents: the pediatrician at the front lines. Pediatr Ann 2018; 47:e261-5. $\underline{\text { Crossref }}$

55. Wagner KD. Pharmacotherapy for major depression in children and adolescents. Prog Neuropsychopharmacol Biol Psychiatry 2005;29:819-26. Crossref

56. Hammad TA, Laughren T, Racoosin J. Suicidality in pediatric patients treated with antidepressant drugs. Arch Gen Psychiatry 2006;63:332-9. $\underline{\text { Crossref }}$

57. Temple R; US Food and Drug Administration. [Letter to TF Kline, SmithKline Beecham Pharmaceuticals, Collegeville, PA; regarding Proposed Pediatric Study Request]. US Food and Drug Administration, Silver Spring, MD; April 29, 1999. Available at: http://bit.ly/2IaTfri (accessed February 26, 2019).

58. Gören JL. Antidepressants use in pediatric populations. Expert Opin Drug Saf 2008;7:223-5. Crossref

59. Cheung A, Sacks D, Dewa CS, Pong J, Levitt A. Pediatric prescribing practices and the FDA blackbox warning on antidepressants. J Dev Behav Pediatr 2008;29:213-15. $\underline{\text { Crossref }}$ 
60. Jane Garland E, Kutcher S, Virani A, Elbe D. Update on the use of SSRIs and SNRIs with children and adolescents in clinical practice. J Can Acad Child Adolesc Psychiatry 2016;25:4-10.

61. Locher C, Koechlin H, Zion SR, et al. Efficacy and safety of selective serotonin reuptake inhibitors, serotonin-norepinephrine reuptake inhibitors, and placebo for common psychiatric disorders among children and adolescents: a systematic review and metaanalysis. JAMA Psychiatry 2017;74:1011-20. Crossref

62. Cheung A, Zuckerbrot RA, Jensen PS, Laraque D, Stein REK; GLAD-PC Steering Group. Guidelines for adolescent depression in primary care (GLAD-PC): Part II. Treatment and ongoing management. Pediatrics 2018;141: pii: e20174082. $\underline{\text { Crossref }}$

63. Dubicka B, Wilkinson PO. Latest thinking on antidepressants in children and young people. Arch Dis Child 2018;103:720-1. $\underline{\text { Crossref }}$

64. Wagner KD, Ambrosini P, Rynn M, et al. Efficacy of sertraline in the treatment of children and adolescents with major depressive disorder: two randomized controlled trials. JAMA 2003;290:1033-41. $\underline{\text { Crossref }}$

65. Wagner KD, Robb AS, Findling RL, Jin J, Gutierrez MM, Heydorn WE. A randomized, placebo-controlled trial of citalopram for the treatment of major depression in children and adolescents. Am J Psychiatry 2004;161:1079-83. $\underline{\text { Crossref }}$

66. Keller MB, Ryan ND, Strober M, et al. Efficacy of paroxetine in the treatment of adolescent major depression: a randomized, controlled trial. J Am Acad Child Adolesc Psychiatry 2001;40:762-72. Crossref

67. ParentsMedGuide.org. PhysiciansMedGuide. The use of medication in treating childhood and adolescent depression: information for physicians. Available at: http://bit.ly/2WaaaiD (accessed February 26, 2019).

68. Moen MD, McKeage K, Plosker GL, Siddiqui MA. Imatinib: a review of its use in chronic myeloid leukaemia. Drugs 2007;67:299-320. $\underline{\text { Crossref }}$

69. Norris RE, Adamson PC. Challenges and opportunities in childhood cancer drug development. Nat Rev Cancer 2012;12:776-82. Crossref

70. Behrman RE; US Food and Drug Administration. [Letter to Eli Lilly and Company, Lilly Corporate Center, Indianapolis, IN; regarding Proposed Pediatric Study Request]. US Food and Drug Administration, Silver Spring, MD; April 29, 1999. Available at: http://bit.ly/2WldFrx (accessed February 26, 2019).

71. Warwick AB, Malempati S, Krailo M, et al. Phase 2 trial of pemetrexed in children and adolescents with refractory solid tumors: a Children's Oncology Group study. Pediatr Blood Cancer 2013;60:237-41. Crossref
72. Casanova M, Enis Özyar E, Patte C, et al. International randomized phase 2 study on the addition of docetaxel to the combination of cisplatin and 5-fluorouracil in the induction treatment for nasopharyngeal carcinoma in children and adolescents. Cancer Chemother Pharmacol 2016;77:289-98. Crossref

73. Kamran SC, Riaz N, Lee N. Nasopharyngeal carcinoma. Surg Oncol Clin N Am 2015;24:547-61. Crossref

74. Brennan B. Nasopharyngeal carcinoma. Orphanet J Rare Dis 2006;1:23. Crossref

75. US Food and Drug Administration. Pediatric exclusivity granted. April 2016. Available at: http://bit.ly/ 2XkTfet (accessed May 21, 2019).

76. US Food and Drug Administration. Clinical review: s NDA 20-038 for fludarabine phosphate. Available at: http://bit.ly/2QGJO6A (accessed February 26, 2019).

77. Fraser C, Brown P, Megason G, et al. Open-label bendamustine monotherapy for pediatric patients with relapsed or refractory acute leukemia: efficacy and tolerability. J Pediatr Hematol Oncol 2014;36: e212-18. $\underline{\text { Crossref }}$

78. Kamihara J, Nyborn JA, Olcese ME, Nickerson T, Mack JW. Parental hope for children with advanced cancer. Pediatrics 2015;135:868-74. $\underline{\text { Crossref }}$

79. US Food and Drug Administration. Highlights of prescribing information: Clolar $\AA$ (clofarabine) Available at: http://bit.ly/2HQGTpk (accessed February 26, 2019).

80. Li JS, Eisenstein EL, Grabowski HG, et al. Economic return of clinical trials performed under the pediatric exclusivity program. JAMA 2007;297:480-8. $\underline{\text { Crossref }}$

81. Adamson PC. Improving the outcome for children with cancer: development of targeted new agents. CA Cancer J Clin 2015;65:212-20. Crossref

82. Avramis VI, Champagne J, Sato J, et al. Pharmacology of fludarabine phosphate after a phase I/II trial by a loading bolus and continuous infusion in pediatric patients. Cancer Res 1990;50:7226-31.

83. Avramis VI, Wiersma S, Krailo MD, et al. Pharmacokinetic and pharmacodynamic studies of fludarabine and cytosine arabinoside administered as loading boluses followed by continuous infusions after a phase I/II study in pediatric patients with relapsed leukemias. The Children's Cancer Group. Clin Cancer Res 1998;4:45-52.

84. Jeha S, Gaynon PS, Razzouk BI, et al. Phase II study of clofarabine in pediatric patients with refractory or relapsed acute lymphoblastic leukemia. J Clin Oncol 2006;24:1917-23. $\underline{\text { Crossref }}$

85. Moreno L, Casanova M, Chisholm JC, et al. Phase I results of a phase I/II study of weekly nab-paclitaxel in paediatric patients with recurrent/refractory solid 
tumours: a collaboration with innovative therapies for children with cancer. Eur J Cancer 2018;100:2734. Crossref

86. Pappo AS. Pediatric melanoma: the whole (genome) story. Am Soc Clin Oncol Educ Book 2014:e432-5. Crossref

87. Benjamin DK Jr, Smith PB, Jadhav P, et al. Pediatric antihypertensive trial failures: analysis of end points and dose range. Hypertension 2008;51:834-40. Crossref

88. Boots I, Sukhai RN, Klein RH, et al. Stimulation programs for pediatric drug research - do children really benefit? Eur J Pediatr 2007;166:849-55. Crossref

89. Christensen ML, Franklin BE, Momper JD, Reed MD. Pediatric drug development programs for type 2 diabetes: a review. J Clin Pharmacol 2015;55:731-8. Crossref

90. Philip AGS. The evolution of neonatology. Pediatr Res 2005;58:799-815. $\underline{\text { Crossref }}$

91. Iosifidis E, Papachristou S, Roilides E. Advances in the treatment of mycoses in pediatric patients. $\mathrm{J}$ Fungi (Basel) 2018;4:115. Crossref

92. Chitnis T, Ghezzi A, Bajer-Kornek B, Boyko A, Giovannoni G, Pohl D. Pediatric multiple sclerosis: escalation and emerging treatments. Neurology 2016; 87(9 Suppl 2):S103-9. $\underline{\text { Crossref }}$

93. Seyberth HW. Probleme der Arzneimittelanwendung bei Kindern [Problems of prescription drug use in children]. Deutsches Ärzteblatt 2009;106:23-4. Available at: http://bit.ly/2Iholxj (accessed February 26, 2019). [German]

94. Turner S, Nunn AJ, Fielding K, Choonara I. Adverse drug reactions to unlicensed and off-label drugs on paediatric wards: a prospective study. Acta Paediatr 1999;88:965-8. Crossref

95. Horen B, Montastruc JL, Lapeyre-Mestre M. Adverse drug reactions and off-label drug use in paediatric outpatients. Br J Clin Pharmacol 2002;54:665-70. Crossref

96. Gaspar N, Marshall LV, Binner D, et al. Joint adolescent-adult early phase clinical trials to improve access to new drugs for adolescents with cancer. Ann Oncol 2018;29:766-71. Crossref

97. Geoerger B, Bergeron C, Gore L, et al. Phase II study of ipilimumab in adolescents with unresectable stage III or IV malignant melanoma. Eur J Cancer 2017; 86:358-63. $\underline{\text { Crossref }}$

98. Pearson AD, Pfister SM, Baruchel A, et al. From class waivers to precision medicine in paediatric oncology. Lancet Oncol 2017;18:e394-404. Crossref
99. Pearson AD, Heenen D, Kearns PR, et al. 10-year report on the European paediatric regulation and its impact on new drugs for children's cancers. Lancet Oncol 2018;19:285-7. Crossref

100. Moreno L, Caron H, Geoerger B, et al. Accelerating drug development for neuroblastoma - new drug development strategy: an Innovative Therapies For Children with Cancer, European Network for Cancer Research in Children and Adolescents and International Society of Paediatric Oncology Europe Neuroblastoma project. Expert Opin Drug Discov 2017;12: 801-11. $\underline{\text { Crossref }}$

101. European Medicines Agency. European Medicines Agency decision CW/Oo01/2015 (class waivers decision). Available at: http://bit.ly/2XvS8IY (accessed February 26, 2019).

102. US Food and Drug Administration, Department of Health and Human Services. Best Pharmaceuticals for Children Act and Pediatric Research Equity Act. July 2016 Status Report to Congress. Available at: http://bit.ly/2HRUHzW (accessed February 26, 2019).

103. European Parliament [website]. European Parliament resolution of 15 December 2016 on the regulation on paediatric medicines (2016/2902(RSP)) Available at: http://bit.ly/2ERDJQd (accessed February 26,2019$)$.

104. Kids V Cancer [website]. RACE For Children Act. Research to Accelerate Cures and Equity for Children Act. February 2017. Available at: http://bit.ly/ 2KoxeIq (accessed February 26, 2019).

105. ACCELERATE [website]. The US Pediatric Equity Act and RACE for Children ACT. Available at: http://bit.ly/2HRhax1 (accessed May 22, 2019).

106. Reaman GH. FDARA 2017 and the RACE for Children Act: implications for pediatric cancer drug development. ACCELERATE [website]. Available at: http://bit.ly/2WkDyHL (accessed February 26, 2019).

107. Kids V Cancer [website]. Endorsements of RACE Act. The RACE for Children Act Coalition. Available at: http://bit.ly/2QPoaul (accessed February 26, 2019).

108. Alves C, Silva SF. Partial benefit of anastrozole in the long-term treatment of precocious puberty in McCune-Albright syndrome. J Pediatr Endocrinol Metab 2012;25:323-5.

109. US Food and Drug Administration. Guidance document. Pediatric study plans: content of and process for submitting initial pediatric study plans and amended initial pediatric study plans. Available at: http://bit.ly/2W72rC5 (accessed February 26, 2019). 
110. European Medicines Agency. Paediatric investigation plans: templates, forms and submission dates [Template for scientific document (part B-F)]. Available at: http://bit.ly/2WqpVqV (accessed February 26, 2019).

111. British National Formulary for Children 2018-2019, 13th ed. London, UK: British Medical Journal Publishers; 2018. ISBN: 978-0-85711-336-8.

112. Adamson PC. Unintended consequences of regulatory initiatives in childhood cancer drug development. JAMA Pediatr 2013;167:886-7. $\underline{\text { Crossref }}$

113. Beecher HK. Ethics and clinical research. N Engl J Med 1966;274:1354-60. $\underline{\text { Crossref }}$
114. Rose CD. Ethical conduct of research in children: pediatricians and their IRB (Part 1 of 2). Pediatrics 2017;139:e20163648. Crossref

115. Adashi EY, Walters LB, Menikoff JA. The Belmont Report at 40: reckoning with time. Am J Public Health 2018;108:1345-8. $\underline{\text { Crossref }}$

116. Laughon MM, Benjamin DK Jr. Mechanisms to provide safe and effective drugs for children. Pediatrics 2014;134:e562-3. Crossref

117. Gonzalez D, Melloni C, Yogev R, et al. Use of opportunistic clinical data and a population pharmacokinetic model to support dosing of clindamycin for premature infants to adolescents. Clin Pharmacol Ther 2014;96:429-37. Crossref 